\title{
SUSTENTABILIDADE NA GESTÃO DE RESÍDUOS SÓLIDOS: UM ESTUDO DE CASO EM PINHEIROS (ES)
}

\author{
Israel Francisco Petronetto de Almeida ${ }^{1}$ \\ Jose Geraldo Ferreira da Silva²
}

\begin{abstract}
Resumo: A quantidade de resíduos sólidos descartada pela população avoluma gradativamente, sendo um entrave para os gestores municipais. Um caminho exequível é a coleta dos resíduos sólidos pelos catadores de maneira sistematizada para a reciclagem. Objetivou-se avaliar a contribuição da associação de catadores de recicláveis na Educação Ambiental dos cidadãos do município de Pinheiros (ES). Em relação à metodologia utilizou-se a pesquisa descritiva e pesquisa de campo, a técnica de observação direta e entrevistas, com os associados da associação de catadores de recicláveis, bem como a população do município. Conclui-se que entre os associados o relacionamento interpessoal não é harmonioso, no que tange à população o trabalho desenvolvido pela associação de sensibilização não tem logrado êxito, sendo inescusável repensar formas de Educação Ambiental.
\end{abstract}

Palavras-chave: Resíduos Sólidos; Catadores; Materiais Recicláveis; Gestão.

Abstract: The amount of solid waste discarded by the population gradually increases, being an obstacle for municipal managers. An feasible way is the colletion of solid waste by collectors in a systematic way for recycling. The objective was to evaluate the contribution of the recyclable waste pickers association in the Environmental Education of the citizens of the city of Pinheiros (ES, Brazil). Regarding the methodology, descriptive research and field research, the technique of direct observation and interviews were used, with members of the association of recyclable waste pickers, as well as the population of the municipality. It is a conclused that among the associates the interpersonal relationship is not harmonious, as far as the population is concerned, the work developed by the awareness association has not been successful, and it is unavoidable to rethink ways of Environmental Education.

Keywords: Solid Waste; Collectors; Recyclable Materials; Management.

\footnotetext{
${ }^{1}$ Faculdade Vale do Cricaré. E-mail: petronettoconsultoria@outlook.com Link para o Lattes: http://lattes.cnpq.br/3630712259014122

2 Faculdade Vale do Cricaré. E-mail: j.geraldo525@gmail.com

Link para o Lattes: http://lattes.cnpq.br/8501774122430914
} 


\section{Introdução}

O comportamento humano tem se transformado gradativamente desde os primórdios da humanidade, seja na forma de acumular coisas, até mesmo com o desenvolvimento tecnológico. Atreladas a estas mudanças, modificaramse também as necessidades humanas, considerando que o ser humano a cada dia tem consumido um volume maior de recursos naturais. Nesse sentido, o homem tem dominado paulatinamente a natureza, bem como seus recursos em benefício próprio, sem pensar nas consequências que 0 consumo desenfreado pode impactar o meio ambiente.

Nesse aspecto, concernente às alterações nos modos de produção e consumo, avolumou-se significativamente a produção dos resíduos sólidos, tanto em diversidade e quantidade, especialmente nos centros urbanos (GOUVEIA, 2012). Conforme dados das Nações Unidas do Brasil de 2018, na atualidade são produzidas mais de 2 bilhões de toneladas de lixo por ano no planeta. Consoante com os dados da Associação Brasileira das Empresas de Limpeza Pública e Resíduos Especiais em 2017 foram gerados 78,4 milhões de toneladas de Resíduos Sólidos Urbanos (RSU) no Brasil (ABRELPE, 2018). Os depósitos irregulares dos resíduos sólidos em locais inapropriados desencadearam graves impactos ao meio ambiente e à população.

Assim, Santos (2008) alude que o lixo produzido nos centros urbanos aparece como um obstáculo para as questões ambientais, aliado a outros aspectos como: desflorestamento, aquecimento global e a escassez de água. Nesse sentido, Oliveira e Carvalho (2007) destacam que a saúde humana também é colocada em risco, quando os resíduos sólidos são descartados de maneira irregular, pois alteiam os vetores causadores de doenças ao ser humano, além da contaminação ao solo e da água.

É cediço que para o desenvolvimento sustentável do planeta reciclar torna-se um mecanismo elementar e improtelável no controle e gerenciamento dos resíduos sólidos urbanos. Tendo em vista, que estes materiais recicláveis serão modificados em insumos produtivos. Conforme a Política Nacional de Resíduos Sólidos (PNRS), o ofício das organizações de reciclagem, juntamente com iniciativas de coleta seletiva, e a parceria com os órgãos públicos, iniciaram um modelo de gestão de resíduos.

Houve uma amplificação do lixo em $3 \%$ entre os anos de 2016 e 2017, devido ao despejo em locais inapropriados, como, ruas, terrenos baldios, lixões ou aterros controlados, trazendo consequências prejudiciais à saúde pública e ao meio ambiente. Nessa perspectiva, o trabalho de garimpo de materiais recicláveis nestes espaços há anos mostra-se como possibilidade de trabalho para uma parcela da sociedade que se encontra sem emprego. De certa forma, estes trabalhadores cooperam com o meio ambiente, visto que mitigam com a demanda por recursos da natureza (ABRELPE, 2018).

Não obstante, com a realização deste trabalho de garimpar materiais recicláveis, quer seja na cidade, em aterros, ou até mesmo em lixões, como 
fonte de renda, acaba trazendo como consequências problemas de saúde pública. Haja vista que há o contato direto com materiais infectantes. Mesmo com a precariedade deste trabalho, tendo em vista as condições insalubres de trabalho, esses trabalhadores colaboram com o meio ambiente, uma vez que aquilo que era visto como inútil, ganha uma nova utilidade. Estes indivíduos são os que mais auxiliam para que os recursos naturais não venham minorar. Nesse sentido, há anos uma parcela relevante destes agentes vem entendendo que o ideal é trabalhar conjuntamente em associações ou cooperativas.

Nessa conjuntura, a legislação incentiva à criação de associações ou cooperativas. A profissão de catador atualmente é regimentada. A fundação do Movimento Nacional dos Catadores de Materiais Recicláveis (MNCR) foi propulsora nesta atividade no final dos anos 90, na contemporaneidade conta com associados em todo o Brasil (MNCR, 2020).

O quantitativo de cooperativas e associações de catadores vem aumentando ao longo dos anos em todo o país. O trabalho desenvolvido por estas empresas auxilia na segregação e destinação correta dos resíduos sólidos. E, hodiernamente contam com incentivo e parceria de instituições públicas e privadas. E, na prestação desses serviços, em alguns casos a legislação beneficia com a dispensa de licitação, com isso trazendo maior rapidez no processo de contratação (BRASIL, 1993).

Nesse ínterim, é imprescindível que esta mão de obra entenda e interprete como funcionam os resultados dos controles gerenciais e administrativos, não estritamente à produção, mas também com o controle de entrada e saída de numerários, controle de folha de pagamento, compra de insumos, vencimentos de contratos, custos de produção e manutenção da instituição.

Desta feita, esta pesquisa apresenta-se com a seguinte problemática: A forma de gestão administrativa praticada pela associação de catadores de recicláveis é apropriada? Caso se encerre o contrato com Prefeitura Municipal, com o atual modelo de gestão, a Associação ainda conseguiria se manter ativa?

Justifica-se pela necessidade de um aprofundamento sobre o modelo de gestão adotado pela respectiva instituição de materiais recicláveis, e implicações que podem recair na instituição, caso a empresa tenha o contrato encerrado pelo contratante.

Objetivou contribuir para o aprimoramento gerencial e sustentável da associação, localizada em Pinheiros/ES. Concorrem os seguintes objetivos específicos: identificar a percepção dos gestores e associados sobre o modelo de gestão atualmente adotado; avaliar as políticas administrativas e gerenciais da associação com a utilização do modelo atual de gestão; identificar a

\footnotetext{
${ }^{3}$ História do MNCR. Disponível em: <http://www.mncr.org.br/sobre-o-mncr/sua-historia>. Acesso em: 07 jan. 2020
}

revista brasileira educação ambiental 
percepção dos moradores quanto à associação e à coleta seletiva no município de Pinheiros-ES.

\section{Percurso metodológico}

A pesquisa é de cunho exploratório, método quantitativo, pesquisa de campo e pesquisa bibliográfica. Nesse sentido, Fonseca (2002, p. 20), salienta que:

[...] os resultados da pesquisa quantitativa podem ser quantificados. Como as amostras geralmente são grandes e consideradas representativas da população, os resultados são tomados como se constituíssem um retrato real de toda a população alvo da pesquisa. A pesquisa quantitativa se centra na objetividade. [...] A pesquisa quantitativa recorre à linguagem matemática para descrever as causas de um fenômeno [...].

O local da pesquisa foi a associação de catadores de materiais recicláveis, localizada no município de Pinheiros, no estado do Espírito Santo. Sendo fundada no ano de 2015, possui natureza jurídica de Associação Privada, funcionando de segunda a sábado. Ao todo são 24 associados vinculados à instituição, todos com natureza jurídica, e um profissional não associado que tem a incumbência de ministrar palestras em entidades privadas e escolas, além de visitar as residências, objetivando sensibilizar acerca da importância da separação correta do lixo. A instituição presta serviço de coleta e triagem, de lixo seco e úmido em diversos locais do respectivo município.

Para melhor entender a associação, foi realizado um levantamento dos procedimentos administrativos como: controle de entrada e saída de materiais; controle financeiro; controle patrimonial; gestão de pessoas entre outros, bem como a análise de seu estatuto e do contrato firmado com a prefeitura. Com autorização prévia da associação, aplicou-se um questionário aos 24 associados, exceto ao profissional que ministra palestras, por não fazer parte do quadro de associados. Outro questionário foi aplicado à população do município de Pinheiros, nos bairros atendidos pela coleta de lixo realizada pela associação. O critério adotado para a coleta de dados com a população, para não haver repetição das pessoas da mesma residência, aplicou-se um questionário por domicílio atendido pela coleta de lixo seco, úmido e convencional.

Para maior confiabilidade aos dados da pesquisa, a amostragem foi com nível de confiança de $95 \%$ e margem de erro de $5 \%$, com base nos dados do IBGE de 2010, identificada pelo censo populacional, a amostragem foi aleatória. Buscou-se aplicar 318 questionários, a esta amostra da população, entretanto somente 299 se dispuseram a responder a pesquisa. Percorreram- 
se os 19 bairros do município, exceto a zona rural. Preservando a proporcionalidade do bairro aplicaram-se de 5 a 26 questionários por bairro.

\section{Análise dos dados}

Para melhor elucidar a pesquisa realizada na associação e com a população, nesta seção serão apresentados os resultados das entrevistas realizadas com os 24 associados da associação, bem como os questionários aplicados à amostra da população do município supracitado.

\section{Perfil socioeconômico dos associados}

Para delinear os sujeitos do estudo, foram aplicadas as variáveis correlacionadas aos seguintes aspectos: idade, sexo, escolaridade e renda. Buscou-se a opinião sobre a gestão da instituição, e relativamente à relação interpessoal entre os associados.

Verificou-se que todos os sócios da associação são ex-funcionários de empresas privadas que eram contratadas pela prefeitura para realizar a operacionalização da Usina de Triagem e Compostagem do município.

Contatou-se que há predominância de homens no quadro dos associados, que correspondem a $79 \%$ dos associados. Este resultado é similar ao encontrado por Rezende et al (2019), onde 79\% da amostra é do sexo masculino, entretanto, outros estudos apontam resultados dissemelhantes. Schwengber et al. (2016), em estudo envolvendo 50 catadores de quatro cooperativas, apontam que $64 \%$ dos catadores eram do sexo feminino. Behs (2014), igualmente reforça o predomínio do sexo feminino, com o quantitativo de $75 \%$.

Observa-se na Figura 1, a distribuição dos associados por faixa etária. Verifica-se, que dos 24 entrevistados, 20 entrevistados (83,3\%) estão na faixa de 30 a 45 anos, quase o dobro do percentual apontado por Rezende et al (2019), onde $47 \%$ se enquadravam nesta mesma faixa, porém mais próximo dos resultados apresentados por Behs (2014), onde $62,5 \%$ têm entre 30 e 50 anos de idade. Ainda, dois associados (8,3\%) têm de 18 a 29 anos de idade, um associado (4,2\%) informou ter entre 46 e 60 anos e um (4,2\%) afirmou ter mais de 60 anos de idade. 


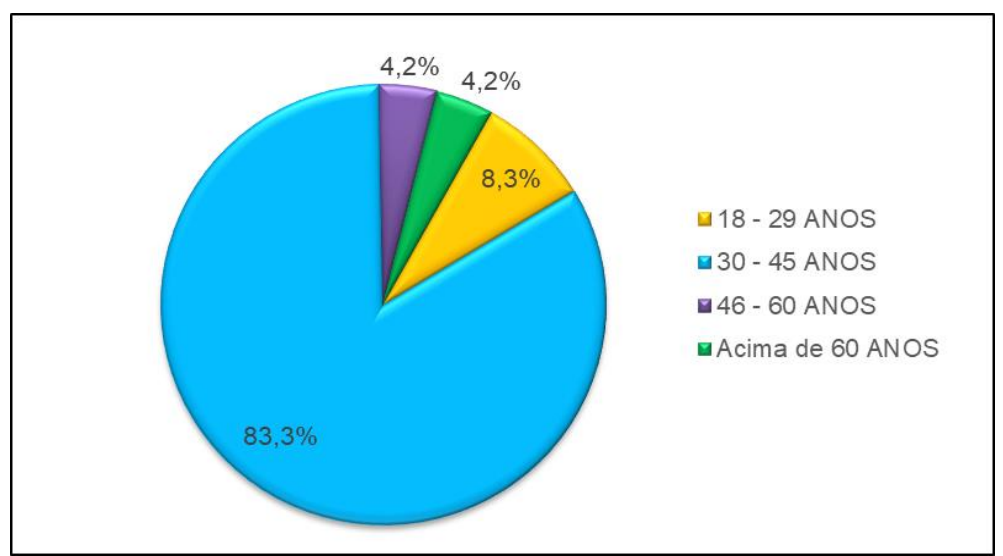

Figura 1: Distribuição dos associados da associação por faixa etária. Fonte: Autores, 2020.

Quanto ao grau de escolaridade, identificou-se que $62,5 \%$ têm o ensino médio e $37,5 \%$ declaram ter o ensino fundamental, não se identificou nenhum associado com escolaridade fora desta faixa. Ao analisar este indicador, percebe-se uma melhora significativa em relação aos obtidos por Rezende et al (2019), 60\% finalizaram o ensino fundamental e $21 \%$ o ensino médio. Os resultados são melhores quando comparados aos de Schwengber et al (2016), no qual $12 \%$ concluíram o ensino médio.

Em se tratando do fator de renda familiar, Figura 2, verifica-se que $87,5 \%$ dos associados possuem renda de um a dois salários-mínimos ${ }^{4}$. Os valores compreendem, o salário mensal pago pela associação aos associados $^{5}$, mais um percentual de $40 \%$ a título de insalubridade 6 . Apesar de não estar computado como salário, os associados também recebem uma cesta básica como benefício. Besen (2011), em pesquisa realizada em 28 municípios do estado de São Paulo, informa que a renda média observada em sua amostra era de 1,05 salários-mínimos, já Schwengber et al. (2016) apontam uma renda média mensal entre 0,91 e 1,25 salários-mínimos ${ }^{7}$.

Ainda com relação à Figura 2, verifica-se um percentual de $12,5 \%$ de associados que afirmam receber entre dois até quatro salários-mínimos. Verifica-se, ainda que nenhum associado, afirmou ter renda maior que 4 salários-mínimos.

Com relação à renda familiar, que é um dos fatores que impactam diretamente no cotidiano destes profissionais, Gadelha Filho (2012) esclarece que a qualidade de vida está relacionada principalmente ao trabalho, à renda e a ter ou não acesso aos serviços básicos como moradia, saúde e educação.

${ }^{4}$ Considerando o Valor do Salário Mínimo de R\$998,00, vigente para o ano de 2019.

5 Estas rubricas são parte integrante das despesas custeadas através de Contrato de Prestação de Serviços, firmado com a Prefeitura Municipal de Pinheiros.

6 Valor de referência, $\mathrm{R} \$ 2095,00$, obtidos no Termo de Referência (TR) para Contratação de Serviços de Coleta de Lixo Seco entre outros 2018, adotado no Termo Aditivo à Convenção Coletiva de Trabalho 2018/2018, celebrado entre a SELURES e SIMIL- ES.

${ }^{7}$ Considerados os valores de salário mínimo referentes aos anos pesquisados. 


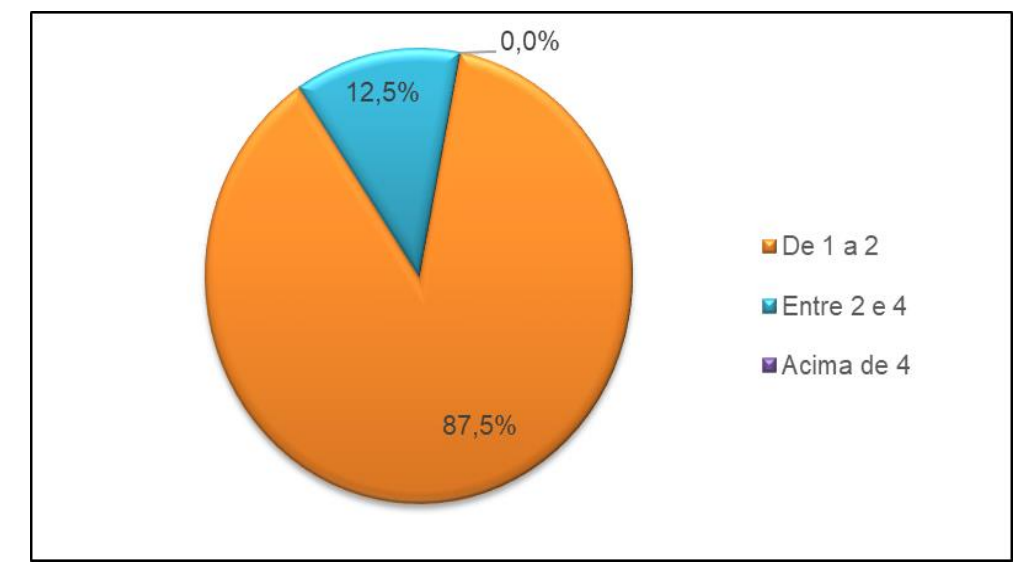

Figura 2: Renda familiar média dos associados da associação, em salário mínimo.

Fonte: Autores, 2019.

Ainda, segundo o IPEA (2013, p. 28), o trabalho em forma de associação tem se propagado nos últimos anos e "[...] tem se disseminado nos últimos anos entre os catadores no Brasil, e que atualmente representa uma possibilidade real de organização produtiva, geração de renda e inclusão social de milhares de famílias envolvidas nesse tipo de trabalho".

Também foi questionado aos associados, sobre como estes avaliam o processo de gestão da Associação, apresentando-se como alternativas, a classificação de Ruim, Razoável, Bom e Ótimo/Excelente. A diretoria da instituição é formada pelo presidente, vice-presidente, secretária geral, $1^{\circ}$ e $2^{\circ}$ tesoureiros, além do conselho fiscal que é formado pelos $1^{\circ}, 2^{\circ}$ e $3^{\circ}$ titulares, ou seja, dos 24 associados, 33\% são membros da diretoria, e estes são responsáveis pelo processo de gestão da associação. Seria razoável então, presumir que o mesmo percentual (33\%) classificasse como ótimo/excelente o nível de satisfação.

Na Figura 3, tem-se o grau de satisfação dos associados a respeito da gestão da associação, considerando todos os membros, inclusive a diretoria. Verifica-se, nesta figura, que $25 \%$ dos associados classificam a gestão como ótima/excelente, enquanto $37,5 \%$ deles classificaram como boa, $25 \%$ como razoável e $12,5 \%$ afirmaram ser ruim o processo de gestão. Salienta-se que estes dados são referentes à gestão anterior da associação ${ }^{8}$.

8 Pouco tempo após a aplicação dos questionários, aproximadamente em janeiro de 2020 (não tivemos acesso à data exata), houve mudança em parte da diretoria da associação, devido a problemas internos. 


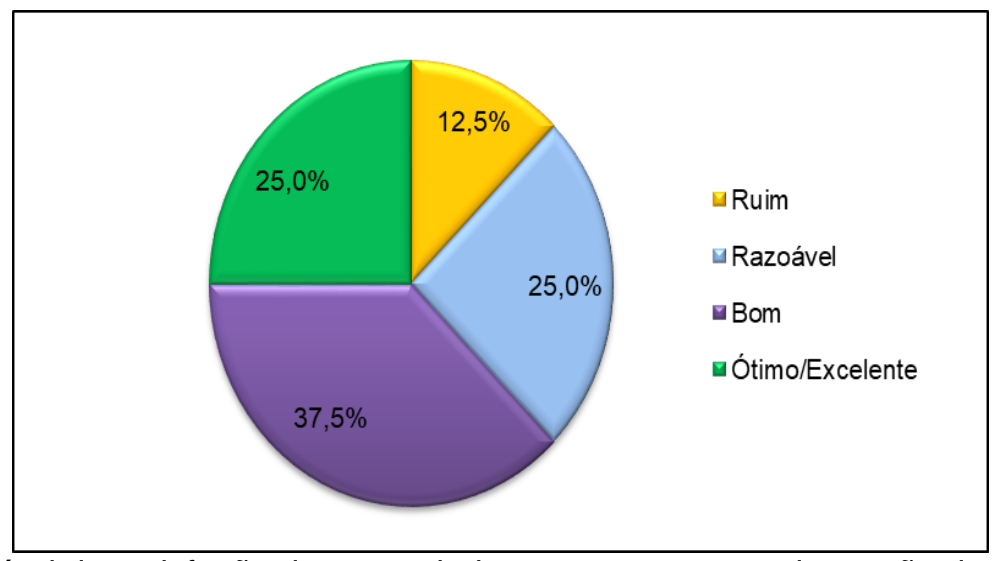

Figura 3: Nível de satisfação dos associados com o processo de gestão da associação.

Fonte: Autores, 2019.

Com vistas a dar maior confiabilidade a este indicador, procedeu-se uma nova análise desconsiderando as respostas de todo o quadro de direção da associação, sendo então, a amostra reduzida aos 16 associados, não membros da diretoria.

Em outra análise por este mesmo prisma, Figura 4, verifica-se que 0 percentual que classifica com bom o processo de gestão, alcançou uma ligeira melhora, saindo de $37,5 \%$ para $43,8 \%$. Entretanto, ao somarmos os percentuais que a classificam como razoável ou ruim este processo, percebese um salto de $18,8 \%$ no grau de insatisfação, passando de $37,5 \%$ para $56,3 \%$.

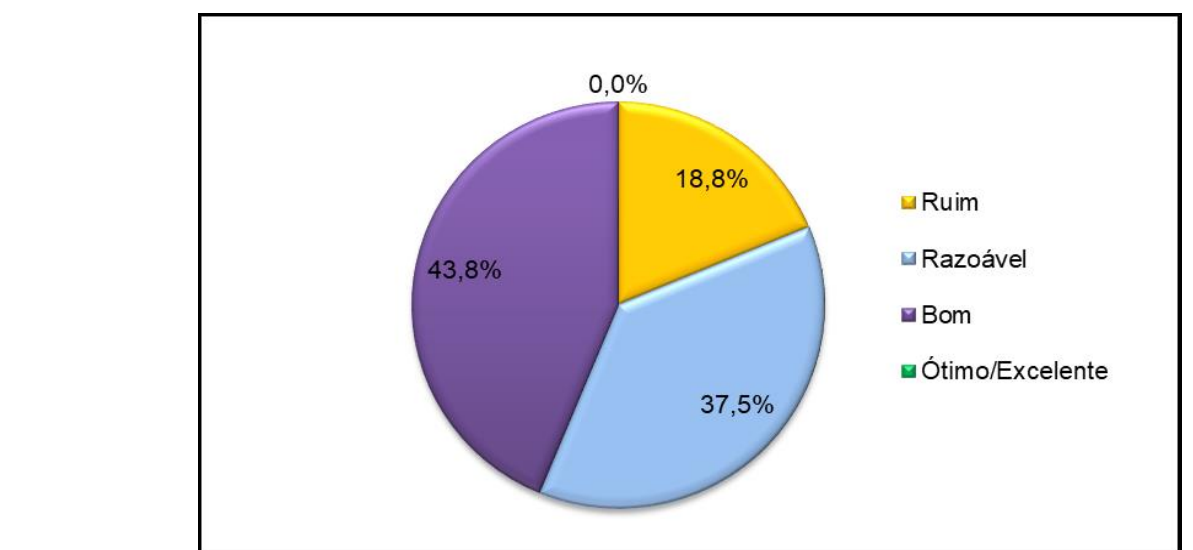

Figura 4: Nível de satisfação com o processo de gestão-excluídos os votos da diretoria.

Fonte: Autores, 2019.

Indubitavelmente o modelo de gestão adotado afetou o resultado da avaliação proposta. Em algum ponto, seus gestores permitiram que o sentimento de associativismo, desse lugar ao individualismo e ao ego, talvez por ainda não entenderem que, neste modelo de negócio, a posição de gestor não lhe coloca em patamar superior a seus pares. 
Partindo destas premissas, foi solicitado aos associados que classificassem o nível da relação entre eles, novamente tendo as opções Ruim, Razoável, Bom e Ótimo/Excelente. Na Figura 5 verifica-se que $58,3 \%$ dos associados consideram as relações interpessoais como "razoável", 20,8\% afirmaram ser "boa", 4,2\% apontam como "ótimo/excelente". Porém 16,7\% dos associados apontaram esta relação como ruim. Assim, verifica-se, que ao somar alguns percentuais, apenas $25 \%$ dos associados avaliaram que 0 relacionamento interpessoal está variando de bom a ótimo, mas $75 \%$ deles classificaram que é de razoável a ruim. Ao classificar o grau de relacionamento como razoável a ruim, denota-se que o sentimento de associativismo, ainda não está completamente arraigado em seu dia a dia, e isto certamente pode ser uma barreira para o crescimento da associação.

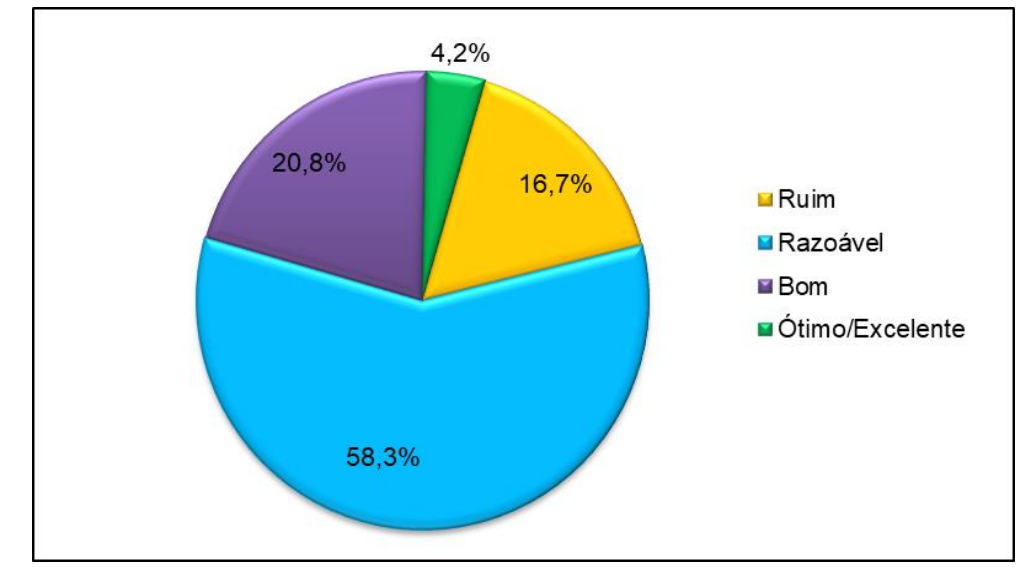

Figura 5: Avaliação dos associados sobre a relação interpessoal na associação. Fonte: Autores, 2019.

É preciso entender que a gestão de uma associação, vai muito além dos controles financeiros, pois engloba também manter as relações pessoais harmoniosas numa entidade desta natureza. Segundo Moscovici (2003, p. 47), "O relacionamento interpessoal entre os líderes e os membros do grupo é um dos fatores mais relevantes na facilitação ou obstância de um clima de confiança, respeito que possibilite relações de harmonia e cooperação".

\section{Percepção da população sobre RSU e o trabalho da associação}

Dentre os itens fixados no contrato firmado entre o município de Pinheiros e a associação, consta a prestação de serviços de Educação Ambiental na gestão de resíduos sólidos.

A Figura 6 mostra a distribuição dos participantes da pesquisa por faixa etária. Verifica-se, que dentre os 299 participantes da pesquisa, $40 \%$ estão na faixa etária entre 40 e 59 anos, 33\% com idade entre 60 e 70 anos, $12 \%$ com idade acima de 70 anos, $11 \%$ dos participantes afirmaram terem idade entre 25 e 39 anos, e $4 \%$ estavam na faixa etária entre 18 e 24 anos. 


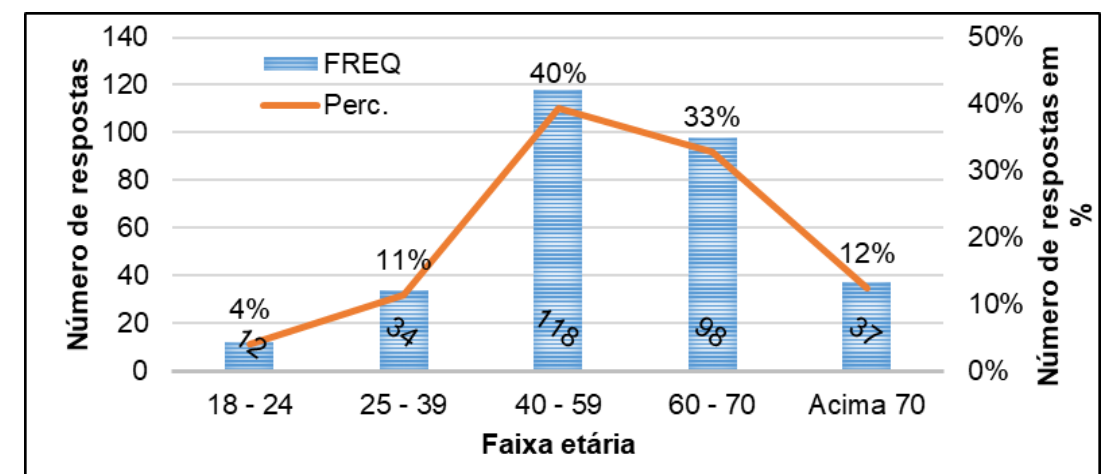

Figura 6: Faixa etária da população entrevistada. Fonte: Autores, 2019.

A Figura 7 mostra as respostas dos participantes da pesquisa, com relação à separação do lixo para coleta seletiva. Verifica-se, nesta figura, que $52 \%$ dos participantes declararam que praticam a separação do lixo para a coleta seletiva, o que facilita o trabalho da associação, $10 \%$ alegaram não fazer a separação por falta de tempo e $11 \%$ alegaram que não fazem por não saber como proceder para tal. Pode-se identificar que 4\% declararam que não fazem separação do lixo por não achar que isto tenha importância, e $23 \%$ declararam que não a realizam por outros motivos.

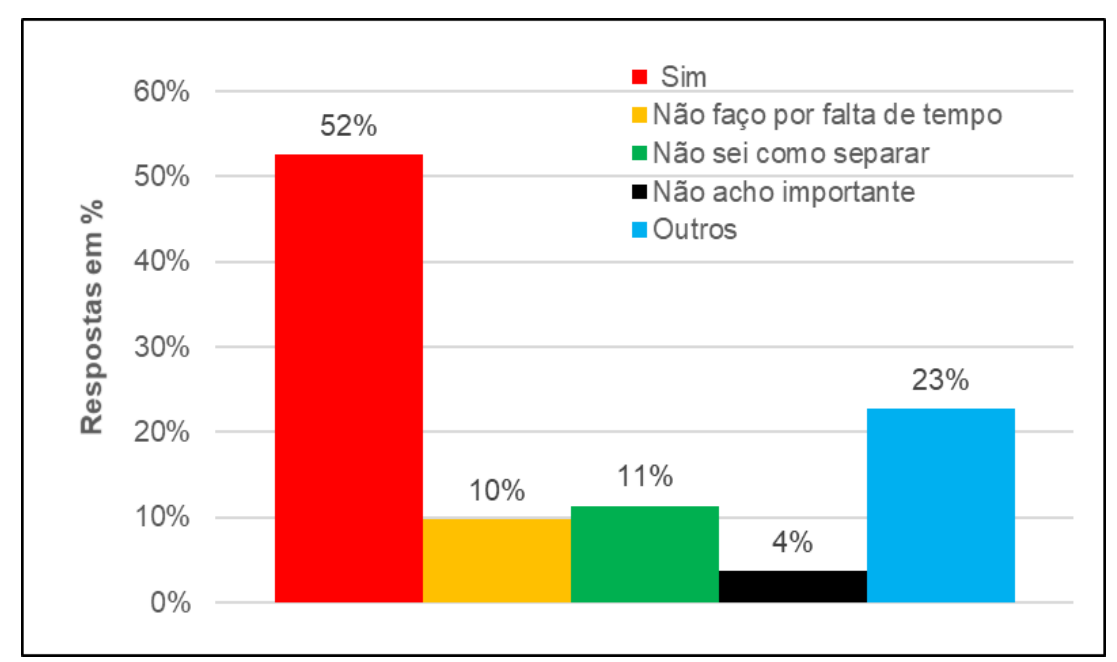

Figura 7: Percentual da população que faz a separação do lixo para a da coleta seletiva.

Fonte: Autores, 2019.

Acerca da correta separação dos resíduos, Richter (2014, p. 26) evidencia que "para o sucesso da coleta seletiva do lixo, é necessária a conscientização da população em relação ao lixo gerado. O cidadão deve reduzir a quantidade de lixo produzido e separá-lo antes da coleta". 
Questionou-se sobre o local onde são depositadas as sacolas contendo o resíduo gerado em sua residência. Conforme mostra a Figura 8, observa-se que $54 \%$ responderam que depositam as sacolas contendo os resíduos na lixeira, $43 \%$ afirmaram colocar na calçada. Somente 3\% disseram que colocam em outro local (não especificado) e nenhum entrevistado afirmou utilizar esquinas ou terrenos vazios, como local para este fim.

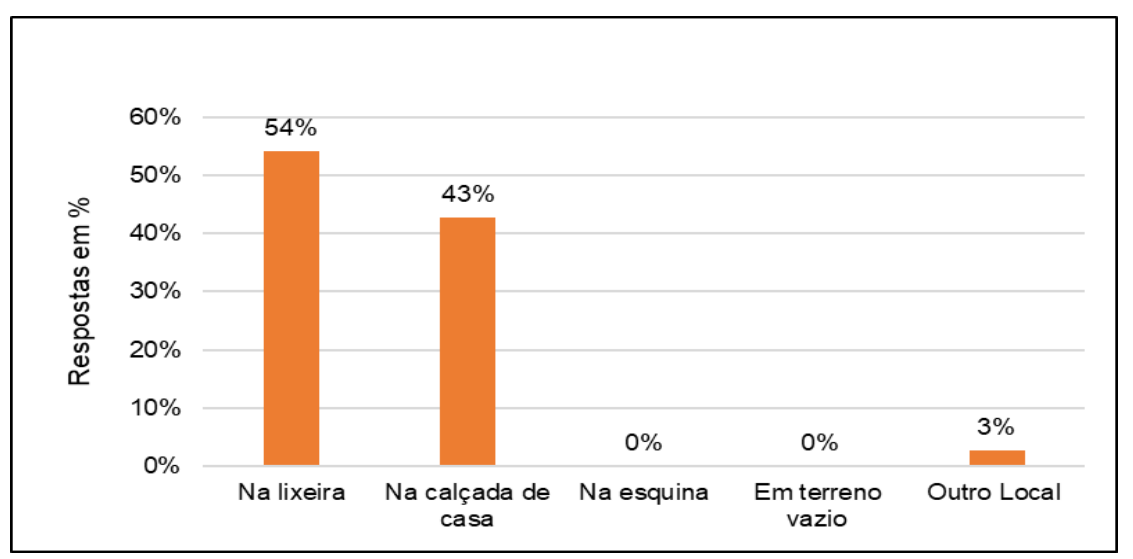

Figura 8: Local onde os entrevistados afirmam depositar o lixo até a coleta. Fonte: Autores, 2019.

Ao considerarmos estes dados, percebe-se um percentual nada animador, de pessoas que agem de forma errada em relação a esta questão, depositando sacolas de lixo nas calçadas, onde é fácil o acesso de animais, que em busca de restos de comida, danificam as embalagens deixando exposto seu conteúdo. Esta atitude causa problemas de mau cheiro e a presença de ratos e insetos.

Segundo Mucelin e Belini (2008, p. 113), "mesmo contemplando casos de agressões ao ambiente, os hábitos cotidianos concorrem para que 0 morador urbano não reflita sobre as consequências de tais hábitos, mesmo quando possui informações a esse respeito".

$\mathrm{Na}$ esteira deste pensamento, surge o próximo questionamento, "Em sua opinião, qual a maior consequência da disposição incorreta do lixo"? Verificase, na Figura 9, que $45 \%$ afirmaram que o mau cheiro é a principal consequência da deposição incorreta do lixo, 33\% afirmaram que isto favorece a proliferação de ratos e insetos, $15 \%$ afirmam que esta atitude pode causar riscos à saúde humana e 7\% afirmaram que a destinação incorreta do lixo pode causar contaminação do solo e água. 


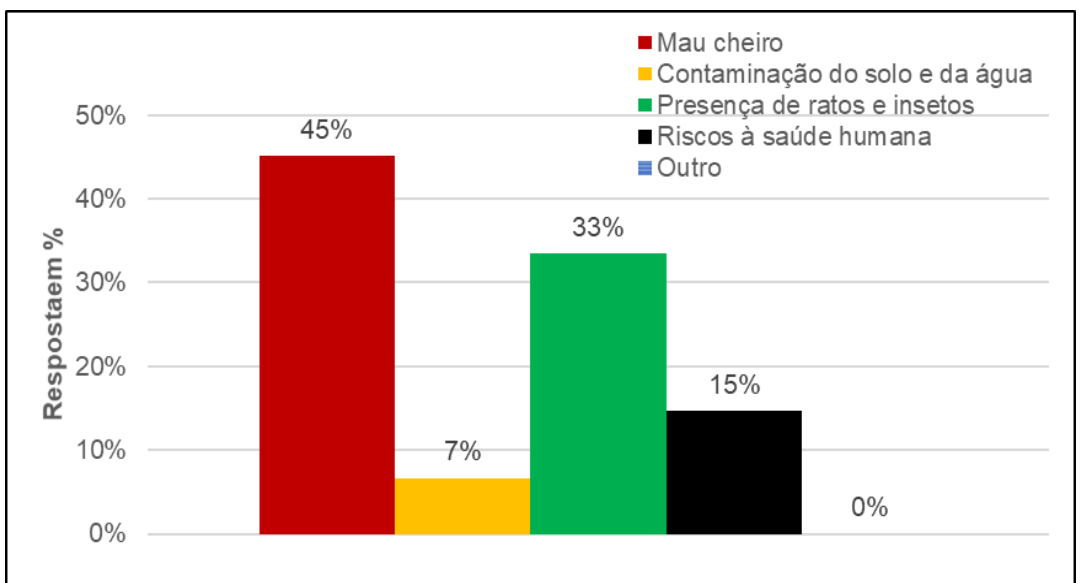

Figura 9: Consequências apontadas pelos entrevistados sobre a disposição incorreta do lixo.

Fonte: Autores, 2019.

Observa-se que, mesmo tendo consciência dos problemas advindos da disposição incorreta do lixo, em especial, o mau cheiro e a proliferação de ratos e insetos foram as respostas mais assinaladas, ainda assim, insistem em depositar o lixo em local incorreto.

Não se pode aqui evidenciar que estes hábitos são decorrentes da falta de informação, haja vista que a associação mantém um colaborador específico para este fim, que é orientar a população sobre Educação Ambiental. Entretanto, se estas atitudes ainda são recorrentes, mesmo em parte da população, restaram então alguns questionamentos a serem feitos.

Desta forma, apesar de haver um funcionário na associação para realizar as atividades de divulgação do serviço de coleta seletiva e de fazer a sensibilização da população através de trabalhos de Educação Ambiental, verifica-se que este trabalho conseguiu atingir, até o momento, apenas $52 \%$ da região. Assim é preciso repensar o trabalho que está sendo realizado e a forma que é levado à população, para que os cidadãos da região possam aderir à coleta seletiva realizada pela associação.

A próxima pergunta objetivou indagar aos moradores se conheciam a associação do município. Neste quesito, 90,3\% afirmaram conhecer a associação, enquanto $9,7 \%$ alegaram não conhecer a entidade, o desconhecimento mesmo parecendo pequeno devido ao tamanho da amostra, acende um sinal de alerta para a associação em relação aos seus objetivos e metas, tendo em vista que sua atuação neste mercado ocorre há mais de cinco anos e diariamente em toda a zona urbana.

A partir deste ponto, tivemos nossa amostra reduzida para 270 pessoas, tendo em vista que, os outros 29 entrevistados, por desconhecerem a associação, não estariam aptos a responder as próximas questões. A próxima pergunta deu-se em relação ao trabalho de reciclagem desenvolvido pela associação. Acerca desta questão, $63 \%$ afirmaram conhecer este trabalho feito pela associação e $34 \%$ responderam que não conhecem. 
Nasce aqui outro problema, e que deve ser ponderado pela associação, refere-se à eficácia de seu planejamento estratégico, no tocante à efetividade das ações de divulgação e Educação Ambiental realizada. Trabalhar o conhecimento deste assunto deve ser parte preponderante quando se tratam dos objetivos e metas da instituição, tendo em vista não só atender a parte contratual, como também dizer que seus resultados futuros, dependem quase que diretamente deste item.

É salutar lembrar sempre sobre os benefícios trazidos pela reciclagem. Gadelha Filho (2012, p. 32) nos recorda que "[...] a produção a partir da reciclagem utiliza menos energia, matéria-prima, recursos hídricos, reduzindo os custos de controle ambiental e os de disposição final de lixo". Entretanto, é imprescindível lembrar-se também que, para que este processo aconteça, a participação popular é fundamental.

A associação mantém um colaborador para trabalhar a sensibilização, junto à população, abordando sobre esses benefícios, bem como para promover palestras no sentido de Educação Ambiental. E foi com este intuito que se lançou o seguinte questionamento: "Você participou de alguma ação ou palestra da associação"? Verifica-se na Figura 10, que 50\% das pessoas afirmaram já haver recebido panfletos da associação e acharam muito interessante, $29 \%$ disseram já terem participado de palestras oferecidas pela associação. Percebe-se que $79 \%$ dos moradores já participaram de algum evento ou já tiveram contato com algum material educativo da associação.

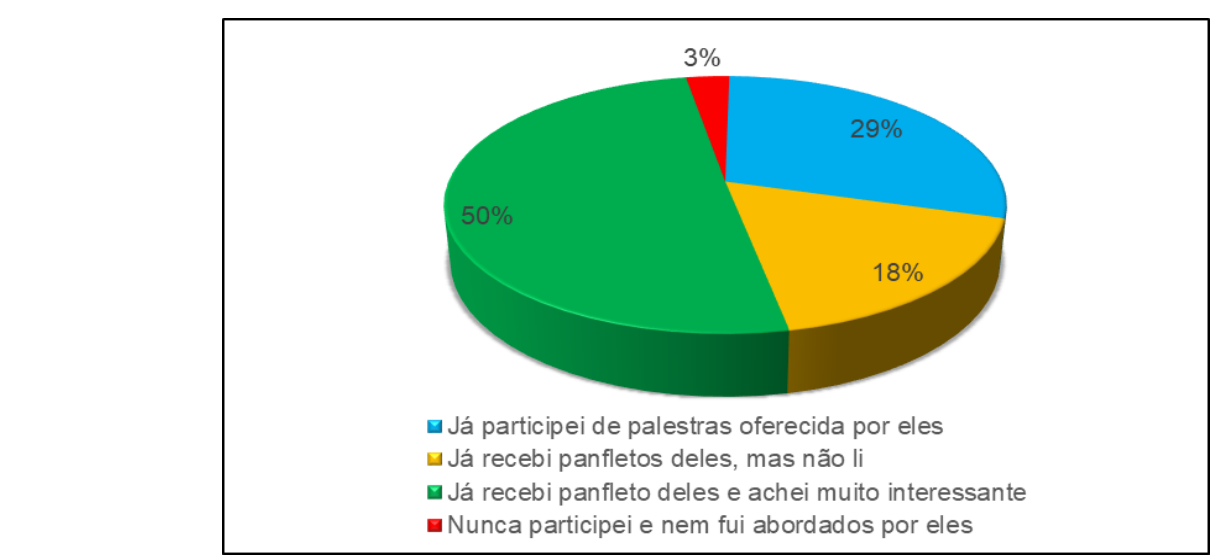

Figura 10: Participação da população entrevistada em ações ou palestras da associação. Fonte: Autores, 2019.

Já na contramão, verifica-se, ainda nesta figura, que $18 \%$ dos moradores relatam ter recebido os panfletos, porém nem chegaram a lê-los, e $3 \%$ afirmam que nunca participaram de nenhum evento oferecido, tampouco foram abordados por alguém da entidade. A soma destes dois últimos percentuais corrobora para o fato de que, os gestores da associação precisam rever, não só a eficiência das metodologias de divulgação do seu trabalho, 
como também a efetividade dos resultados apresentados neste campo. A linha tênue que existe entre estes dois pontos, pode vir a ser o diferencial para a imagem da associação, do ponto de vista dos usuários de seus serviços, e consequentemente, em uma possível futura renovação de contrato com o município.

Outro fator de extrema relevância, está na avalição da população em relação ao trabalho desempenho do trabalho da associação, tema do último questionamento. Neste aspecto quando indagados sobre o grau de importância do trabalho da associação para a população do município, identifica-se, na Figura 11 , que $58 \%$ dos entrevistados qualificaram como muito importante, $21 \%$ disseram que é importante.

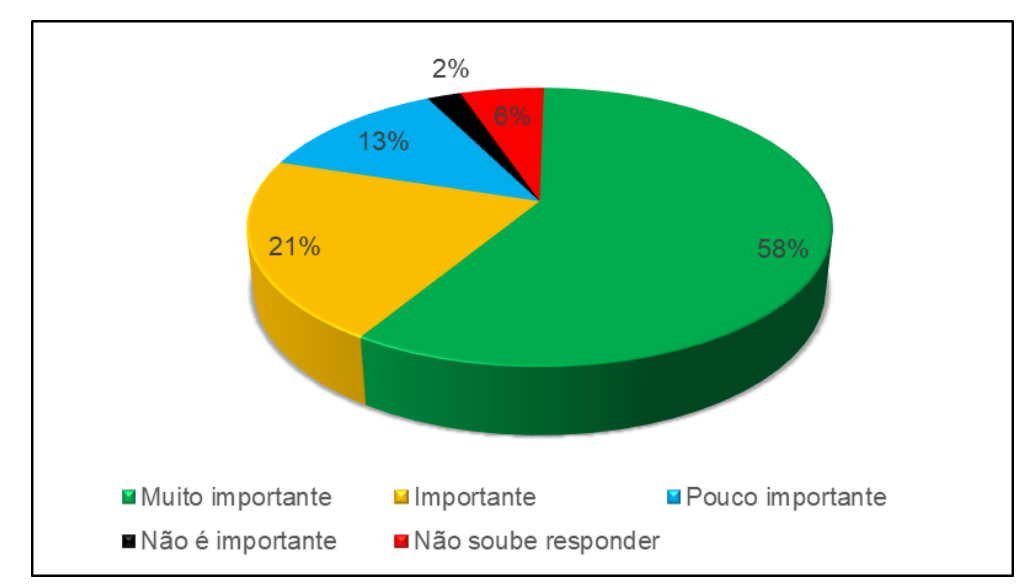

Figura 11: Grau de importância atribuído pelos entrevistados sobre o trabalho da associação para o município. Fonte: Autores, 2019.

Verifica-se ainda que $13 \%$ dos moradores acreditam que o trabalho da associação é pouco importante para a população, $2 \%$ julgam não ser importante e $6 \%$ não souberam responder. Podemos constatar este fato, quando no questionamento anterior, o mesmo percentual, ou seja, $21 \%$ dos moradores não se viram estimulados, com os métodos utilizados, a abraçar a missão da associação. Quando 18\% afirmam não terem nem lido os panfletos distribuídos e outros 3\% informam que sequer foram contatados pela associação, não se pode esperar que estes, atribuam algum grau de importância ao trabalho desenvolvido pela associação.

Richter (2014, p. 27), assevera que "para o sucesso do empreendimento é necessária a cooperação mútua de várias pessoas, desempenhando um trabalho árduo e contínuo, envolvendo a população sobre a conscientização da importância do programa", e isso só é possível através de um processo educacional continuado e persistente. 


\section{Considerações finais}

Diante do exposto até aqui, fazer reflexões acerca da ausência de entendimento da rotina de gestão de uma instituição é salutar para o bom andamento da mesma, principalmente, em se tratando de uma entidade voltada para a coleta de resíduos sólidos. Nesse sentido, o papel do gestor é basilar para qualquer associação, e seu sucesso dependerá de decisões congruentes. A clareza nos custos operacionais de uma instituição, tem relação direta nos resultados, o desconhecimento destes gastos acarretará em grandes riscos para a associação.

A gestão atual não tem agradado aos associados, pois não há clareza na prestação de contas, estas informações são repassadas no dia da assembleia. O associado só terá informações extras se deslocando ao setor de contabilidade da instituição. O relacionamento interpessoal entre os associados é outro obstáculo apresentado, análogo está a ausência de sentimento de associativismo.

Percebeu-se que existem fragilidades na instituição, em relação ao trabalho desenvolvido de Educação Ambiental na região, sendo primordial ações mais eficazes que as atuais, considerando que uma parcela da população não tem se sensibilizado para as questões ambientais. Existe uma minoria que não conhece a existência da associação, isso torna-se preocupante, pois a entidade existe há mais de cinco anos. Uma quantidade relativamente considerável desconhece o trabalho desenvolvido, alguns que conhecem não demostram interesse pelos problemas ambientais, outros acreditam não ser relevante o trabalho de coleta de resíduos sólidos.

Nessa direção, tratar das questões ambientais requer um trabalho articulado. De uma maneira de todos entendam seu papel na preservação do planeta e dos recursos naturais. $O$ fato de a população pesquisada desconhecer 0 trabalho desenvolvido pela associação mostra-se uma ineficiência na metodologia de difusão vigente.

Sendo assim, em uma sociedade que está em transformação progressivamente, e com estas mudanças o planeta padece com a quantidade de resíduos sólidos descartados, ter uma gestão que entenda seu papel na sustentabilidade do meio ambiente é substancial para tomadas de decisões acertadas. Além de propiciar que a associação trabalhe com independência e autonomia, visando minimizar situações de declínio, ou até mesmo, sua extinção. 


\section{Referências}

ASSOCIAÇÃO BRASILEIRA DAS EMPRESAS DE LIMPEZA PÚBLICA E RESÍDUOS ESPECIAIS-ABRELPE, 2018, Panorama dos Resíduos Sólidos no Brasil. Disponível em: $<$ http://abrelpe.org.br/pdfs/panorama/panorama abrelpe 2017.pdf >. Acesso em: 07 fev. 2019.

BEHS, I. M. (Des)Conexões na Educação para a Saúde Integral: Um Estudo de Caso com Catadores de uma Cooperativa. 2014. 154 f. Tese (Doutorado em Educação) - Faculdade de Educação, Pontifícia Universidade Católica do Rio Grande do Sul, Porto Alegre, 2014

BESEN, G. R. Coleta seletiva com inclusão de catadores: construção participativa de indicadores e índices de sustentabilidade. 2011. $275 \mathrm{f}$. Tese de doutorado (Doutorado em Saúde Pública). Programa de Pós-graduação em Saúde Pública, Faculdade de Saúde Pública da USP, São Paulo.

BRASIL. Lei no 8.666, de 21 de junho de 1993. Regulamenta o art. 37, inciso $\mathrm{XXI}$, da Constituição Federal, institui normas para licitações e contratos da Administração Pública e dá outras providências.

FONSECA, J. J. S. Metodologia da pesquisa científica. Fortaleza: UEC, 2002. Apostila.

GADELHA FILHO, J. R. Reciclagem, questão ambiental e inclusão social no Amazonas: o caso dos catadores de papelão. 2012. 126 f. Dissertação (Mestrado em Ciências Ambientais) - Universidade Federal do Amazonas, 2012. Disponível em: <https://tede.ufam.edu.br/bitstream/tede/2537/1/joel.pdf>. Acesso em: 02 mar. 2020.

GOUVEIA, N. Resíduos sólidos urbanos: impactos socioambientais e perspectiva de manejo sustentável com inclusão social. São Paulo, 2012. Disponível em: <http://www.scielo.br/pdf/csc/v17n6/v17n6a14.pdf>. Acesso em: 04 fev. 2020.

INSTITUTO BRASILEIRO DE GEOGRAFIA E ESTATÍSTICA. Censo demográfico - 2010. Rio de Janeiro, 2010. Disponível em: $<$ https://cidades.ibge.gov.br/brasil/es/pinheiros/panorama>. Acesso em: $11 \mathrm{abr}$. 2020.

IPEA-INSTITUTO DE PESQUISA ECONÔMICA APLICADA. Situação Social das Catadoras e dos Catadores de Material Reciclável e Reutilizável. Brasília: Ipea, 2013. Disponível em: $<$ http://www.ipea.gov.br/portal/images/stories/PDFs/situacao social/131219 rel atorio situacaosocial mat reciclavel brasil>. Acesso em: 02 mar. 2020.

MOSCOVICl, F. Desenvolvimento Interpessoal: treinamento em grupo, 13 ed, rev. e ampliada. Rio de Janeiro: J. Olympio, 2003. 
MUCELIN, C. A.; BELLINI, M. Lixo e impactos ambientais perceptíveis no ecossistema urbano. Sociedade \& Natureza, Uberlândia, v.20, n.1, p.111-124, jun. 2008.

ONUBR. Humanidade produz mais de 2 bilhões de toneladas de lixo por ano, diz ONU em dia mundial. Disponível em: $<$ https://nacoesunidas.org/humanidade-produz-mais-de-2-bilhoes-de-toneladasde-lixo-por-ano-diz-onu-em-dia-mundial/>. Acesso em: 05 fev. 2019.

OLIVEIRA, M. V. C. de; CARVALHO, A. R. de. Princípios básicos do saneamento do meio. 9ae ed. - São Paulo: Editora Senac São Paulo, 2007.

REZENDE, G.M.; CARDOSO, V.L.; PEREIRA, K.C.; SILVEIRA, F.; ALMEIDA. Anuário da Reciclagem 2017-2018. Disponível em: $<$ http://www.ativgreen.com.br/cempre/anuario da reciclagem.pdf>. Acesso em: 06 set. 2019.

RICHTER, L. T. A importância da conscientização e da coleta seletiva de lixo no município de Palmitos - SC. Universidade Tecnológica Federal do Paraná, Medianeira, $2014 . \quad$ Disponível em: $<$ http://repositorio.roca.utfpr.edu.br/ispui/bitstream/1/4537/1/MD GAMUNI 2014 2 45.pdf $>$. Acesso em: 05 mar. 2020

SANTOS, L. C. dos. A questão do lixo urbano e a geografia. In: $1^{\circ}$ Seminário de Pós-graduação em Geografia, 2008. Rio Claro, Anais. Rio Claro: Editora. p. 1014-1028. 2008.

SCHWENGBER, D.; SOUZA, A.; CARDOSO, J.C.; BIZANI, D. Perfil socioeconômico de profissionais catadores de quatro cooperativas de resíduos sólidos da região metropolitana de Porto Alegre/RS, Brasil. Revista Saúde e Desenvolvimento Humano, Canoas, v. 4, n. 2, 2016. 